\title{
Definition of manufacturability - product of mathematical expressions and fuzzy logic for his early design
}

\author{
Radivoje Antic $^{* 1}$, Slavica Cvetkovic ${ }^{2}$, Branko Pejovic ${ }^{3}$, Milan Cvetkovic ${ }^{4}$ \\ ${ }^{1}$ Higher School of Applied Professional Studies inul. Filip Filipovic 20, 17501 Vranje \\ ${ }^{2,3}$ Slavica Cvetkovic, Branko Pejovic, Faculty of Technical Sciences, Knez Milos Street No. 7, 38220 Kosovska Mitrovica \\ ${ }^{4}$ B. Sc. Engineering, Faculty of Nis \\ *Corresponding authorE-mail: radeantic@open.telekom.rs
}

\begin{abstract}
The paper explaines manufacturability of products for robust design of a new product. Explained mathematical expressions of fuzzy logics describe manufacturability. Provides an example of using the model for the determination of the tmanufacturability.
\end{abstract}

Keywords: Fuzzy logic, manufacturability of products.

\section{Introduction}

In Figure 1 are shown significant parameters of the manufacturaability of products as a whole in terms of making Tip, where you can see that the influential parameter "the conquer of parts in productive system" made up of influential parameters "representation of standard parts," " representation of uninfeced parts and detail parts," "uniformity of parts of products" and "participation already made up parts of the product "[1].

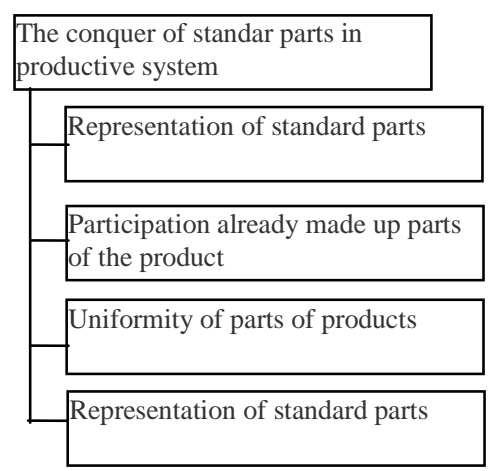

Fig 1: Structure of the parameters "had conquered the parts of products in the production system" [1]

\section{Defining of the mathematical expression for calculating manufacturability of products}

Manufacturability of product (tehnlp) is dependent on degrees of belonging [2,3]: $\mathrm{K}_{\mathrm{p}}, \mathrm{K}_{\mathrm{s}}, \mathrm{K}_{\mathrm{j}}, \mathrm{K}_{\mathrm{t}}, \mathrm{K}_{\mathrm{i}}, \mathrm{K}_{\mathrm{od}}, \mathrm{K}_{\mathrm{ot}}, \mathrm{K}_{\mathrm{r}} \mathrm{K}_{\mathrm{m}} \mathrm{i} \mathrm{K}_{\mathrm{rz}}$. Degrees of belonging have the following meanings:

$2.1 \mathrm{Kp}$ - the degree of repetition,

$2.2 \mathrm{Ks}$ - standard level,

$2.3 \mathrm{Kj}$ - level of uniformity,

$2.4 \mathrm{Kt}$ - the degree of accuracy

$2.5 \mathrm{Kj}$ - degree efficiency weight

$2.6 \mathrm{Kj}$ - the degree of belonging of the cast, 
2.7 Kot - the degree of belonging of to the forging,

$2.8 \mathrm{Kr}$ - the degree of belonging of manual labor,

$2.9 \mathrm{Km}$ - the degree of belonging of mechanical treatment

$2.10 \mathrm{Kv}-$ level of fragmentation.

So, we operate with ten degrees of manufacturability of products. Each of them des not have equal participation. By designing of the technological process in practice it was found that their values have the following relationship:

$\mathrm{K}_{\mathrm{p}}: \mathrm{K}_{\mathrm{s}}: \mathrm{K}_{\mathrm{j}}: \mathrm{K}_{\mathrm{t}}: \mathrm{K}_{\mathrm{i}}: \mathrm{K}_{\mathrm{od}}: \mathrm{K}_{\mathrm{ot}}: \mathrm{K}_{\mathrm{r}}: \mathrm{K}_{\mathrm{m}}: \mathrm{K}_{\mathrm{rz}}=2.5: 3: 1.5: 2: 0.2: 2: 4: 0.2: 1: 0.2$.

Manufacturability tehnl $\mathrm{p}_{\mathrm{p}}$ gets the following expression:

tehnl $\mathrm{p}_{\mathrm{p}}=0,25 \mathrm{~K}_{\mathrm{p}}+0,3 \mathrm{~K}_{\mathrm{s}}+0,15 \mathrm{~K}_{\mathrm{j}}+0,2 \mathrm{~K}_{\mathrm{t}}+0,02 \mathrm{~K}_{\mathrm{i}}+0,2 \mathrm{~K}_{\mathrm{od}}+0,4 \mathrm{~K}_{\mathrm{ot}}+0,02 \mathrm{~K}_{\mathrm{r}}+0,1 \mathrm{~K}_{\mathrm{m}}+0,02 \mathrm{~K}_{\mathrm{rz}}$

Since the manufacturability and fuzzy functions are variable, their total value is the maximum amount of 1 , then the sum of the above ratio equated to 1 , so the expression for the total manufacturability can be written as

tehnl $_{\mathrm{p}}=0,15 \mathrm{~K}_{\mathrm{p}} 0,18 \mathrm{~K}_{\mathrm{s}}+0,094 \mathrm{~K}_{\mathrm{j}}+0,12 \mathrm{~K}_{\mathrm{t}}+0,012 \mathrm{~K}_{\mathrm{i}}+0,12 \mathrm{~K}_{\mathrm{od}}+0,24 \mathrm{~K}_{\mathrm{ot}}+0,012 \mathrm{~K}_{\mathrm{r}}+0,06 \mathrm{~K}_{\mathrm{m}}+0,012 \mathrm{~K}_{\mathrm{rz}}$

Check of the value of the expression is executed in variable values: $0,0.1$ and 1 For the variable value equal to 0 , the technologicality 0 . For the variables equals to 0.1 manufacturaability gets the value 0.1 and if the value of the variable is 1, 1 manufacturability. So manufacturability values as well as its degree of membership range from $0-1$. Degrees of belonging: $\mathrm{K}_{\mathrm{p}}, \mathrm{K}_{\mathrm{s}}, \mathrm{K}_{\mathrm{j}}, \mathrm{K}_{\mathrm{k}}, \mathrm{K}_{\mathrm{od}}, \mathrm{K}_{\mathrm{ot}}, \mathrm{K}_{\mathrm{m}}$ are directly proportional, while $\mathrm{K}_{\mathrm{t}}, \mathrm{K}_{\mathrm{r}}$ and $\mathrm{K}_{\mathrm{v}}$ are inversely proportional and displayed by their expressions:

$\mathrm{K}_{\mathrm{p}}=\mathrm{n}_{\mathrm{p}} / \mathrm{n} ; \mathrm{K}_{\mathrm{s}}=\mathrm{n}_{\mathrm{s}} / \mathrm{n} ; \mathrm{K}_{\mathrm{j}}=\mathrm{n}_{\mathrm{j}} / \mathrm{n} ; \mathrm{K}_{\mathrm{i}}=\mathrm{G}_{\mathrm{k}} / \mathrm{G} ; \mathrm{K}_{\mathrm{od}}=\mathrm{n}_{\mathrm{od}} / \mathrm{n} ; \mathrm{K}_{\mathrm{ot}}=\mathrm{n}_{\mathrm{ot}} / \mathrm{n}, \mathrm{K}_{\mathrm{m}}=\mathrm{n}_{\mathrm{m}} / \mathrm{n}$.

While the degree of belonging: $\mathrm{K}_{\mathrm{r}} ; \mathrm{K}_{\mathrm{t}}$ and $\mathrm{K}_{\mathrm{rz}}$ have expressions:

$\mathrm{K}_{\mathrm{t}}=1-\mathrm{n}_{\mathrm{t}} / \mathrm{n}, \mathrm{K}_{\mathrm{r}}=1-\mathrm{n}_{\mathrm{r}} / \mathrm{n} ; \mathrm{K}_{\mathrm{rz}}=1-\mathrm{V}_{\mathrm{o}} / \mathrm{V}$.

The parameters in the following terms have the following meanings:

$\mathrm{n}$ - the number of new workpieces (which are processed first)

$\mathrm{n}_{\mathrm{p}}$ - number of workpieces that are repeated (already processed earlier in the business process, and have the technical and technological documentation of processing);

$\mathrm{n}_{\mathrm{s}}$ - number of standard business objects (screws, pins ..)

$\mathrm{n}_{\mathrm{i}}$ - number of uniform workpieces (typical);

$\mathrm{V}_{\mathrm{i}}$ - the processed volume of the workpiece;

$\mathrm{V}$ - volume of workpiece;

$\mathrm{Gi}$ - weight of processed workpiece;

$\mathrm{G}$ - weight of preparation workpiece;

$\mathrm{n}_{\mathrm{od}}$ - the number of workpieces which are obtained by casting;

$\mathrm{n}_{\mathrm{ot}}$ - the number of workpieces obtained by forging;

$\mathrm{n}_{\mathrm{m}}$ - the number of workpieces obtained by mechanical processing;

$\mathrm{n}_{\mathrm{t}}$ - number of workpieces with greater accuracy;

$\mathrm{n}_{\mathrm{r}}$ - number of workpieces obtained bz manual processing.

Graphs of the above levels of belonging have the following look at these final stages of belonging.

To be able to monitor the real value of the product manufacturability, it is defined as a function of the number of mechanical parts: $n_{p}, n_{s}, n_{j}, n_{o d}, n_{o t}, n_{m}, n_{t}, n_{r}$. Manufacturability of product is a function of the total weight Gi, the volume of the workpiece $\mathrm{V}_{\mathrm{i}}$. For these we taken number of workpieces of a new product as a constant as the volume and weight of workpiece, $\mathrm{G}$ and $\mathrm{V}$.

New real degree of belonging are marked with $\mathrm{k}$ and are given in graphs in the given function. This is done because the observed structure of a product implements the function. For the construction are required savings in material and time at the mentioned variables. So with new designed parts $n$, one tends to increase the amount of; $n_{p}, n_{s}, n_{j}, n_{t}, n_{\text {od }}, n_{\text {ot }}$ and $n_{m}$ utilization of weight or volume of mechanical parts and reduce $n_{t}$ and $n_{r}$.

\section{Defining fuzzy logics of manufacturability of products}

In defining the fuzzy logic of manufacturability we use its fuzzy production rules: IF $0,15 \mathrm{~K}_{\mathrm{p}}+0,18 \mathrm{~K}_{\mathrm{s}}+0,094 \mathrm{~K}_{\mathrm{j}}+0,12 \mathrm{~K}_{\mathrm{t}}+0,012 \mathrm{~K}_{\mathrm{G}}+0,12 \mathrm{~K}_{\mathrm{od}}+0,24 \mathrm{~K}_{\mathrm{ot}}+0,012 \mathrm{~K}_{\mathrm{r}}+0,06 \mathrm{~K}_{\mathrm{m}}+0,012 \mathrm{~K}_{\mathrm{rz}}=\mathrm{THEN}$ tehnl 


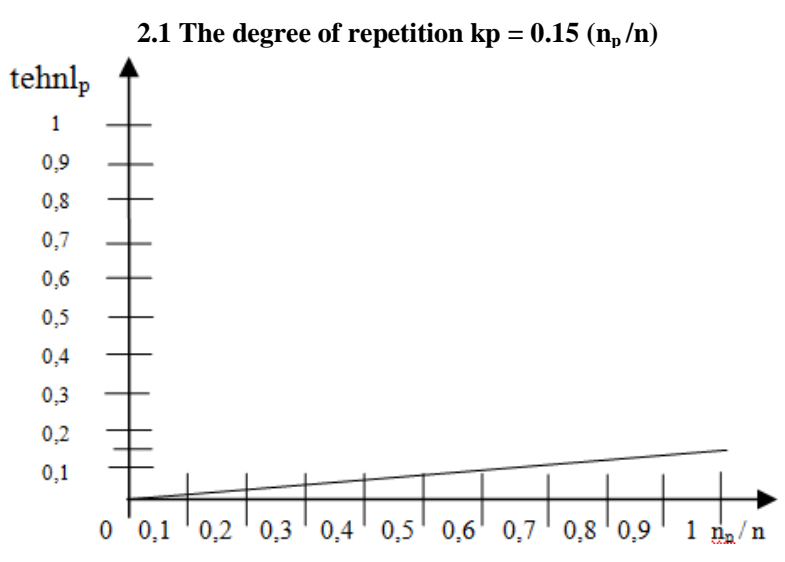

Fig. 2: Graph - degree of repetitions
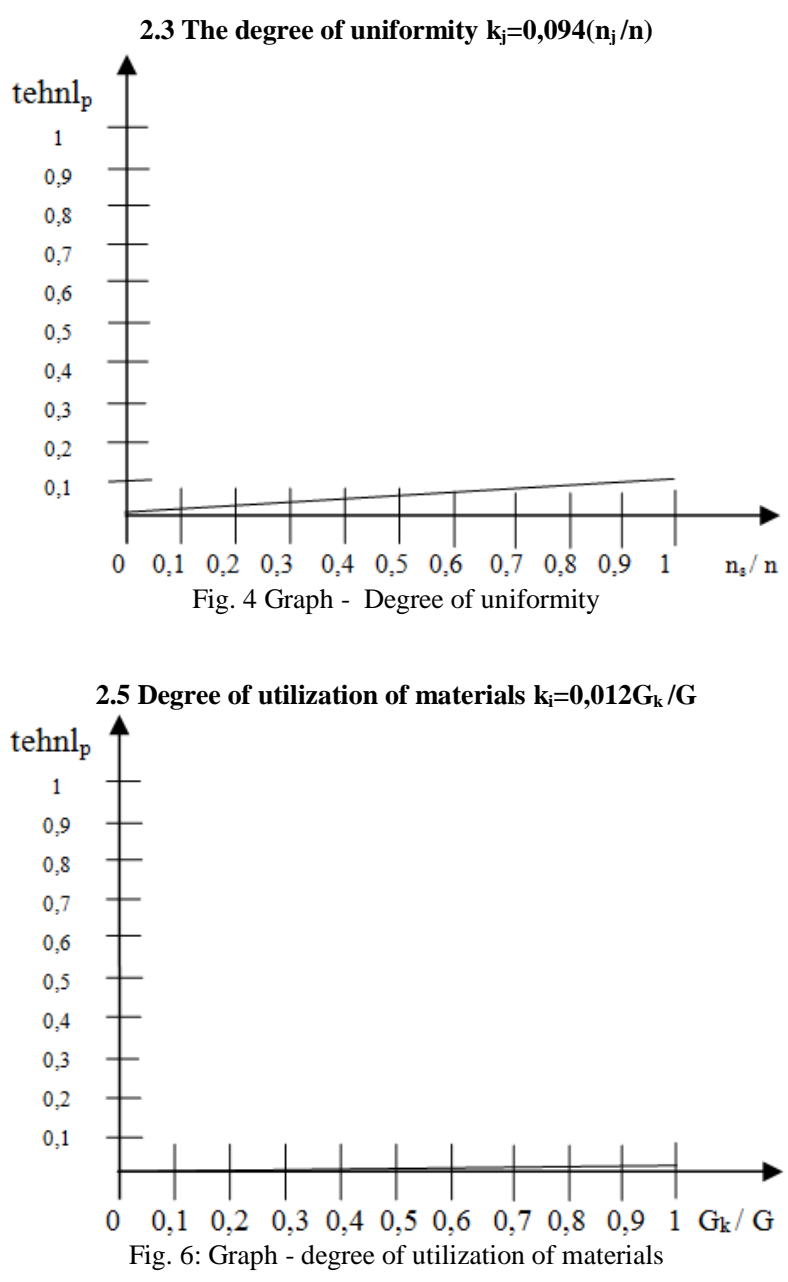
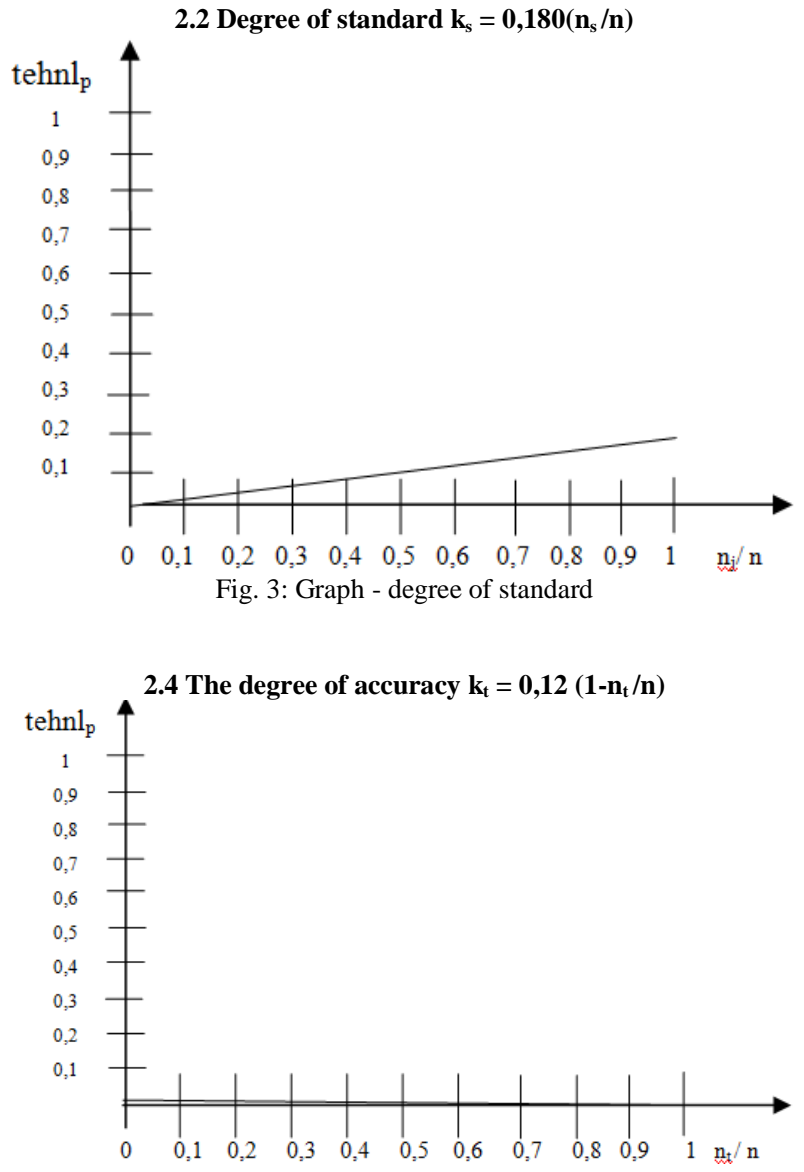

Fig. 5. Graph - degree of accuracy

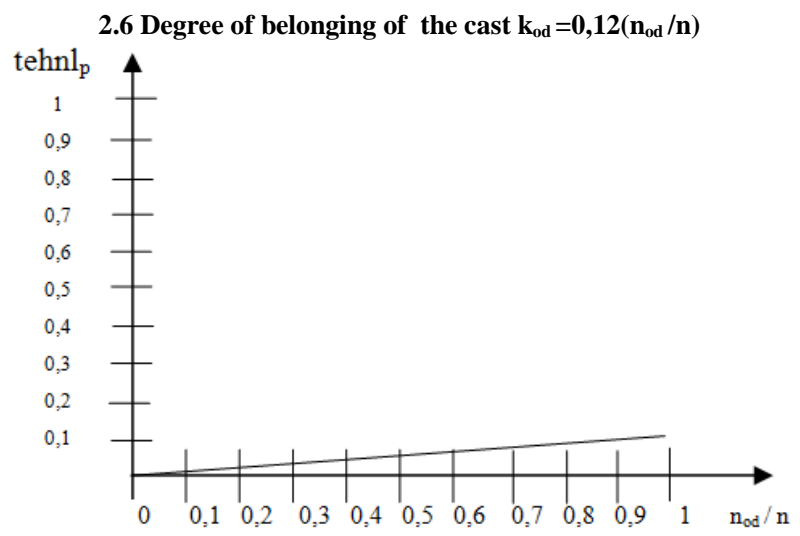

Fig. 7: Graph - degree of belonging of the cast 
2.7 The degree of belonging to forging $k_{o t}=0,24\left(n_{o t} / n\right)$

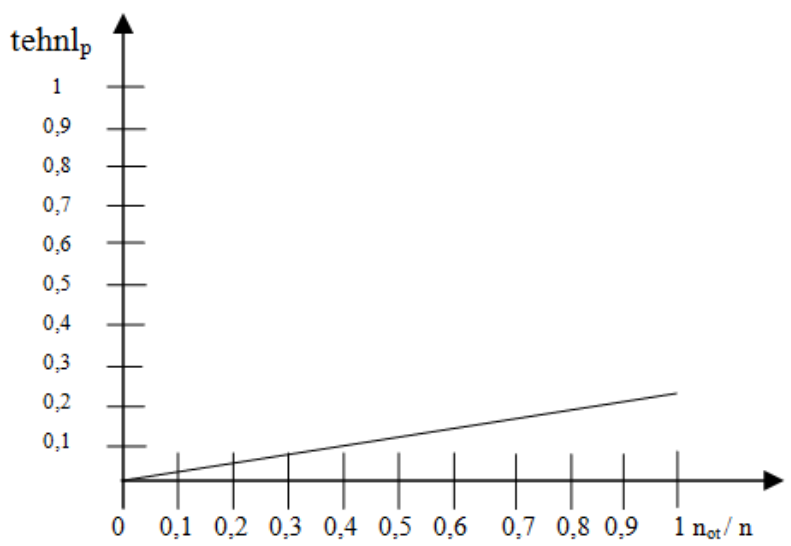

Fig. 8: Graph - degree of belonging of forging
2.8 The degree of belonging of manual processing $k_{r}=0,012\left(1-n_{r} / n\right)$

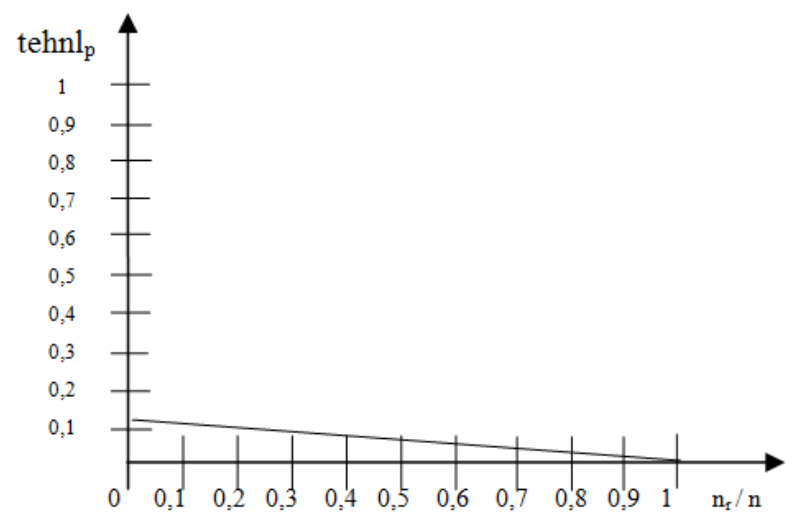

Fig. 9: Graph - degree of belonging of manual processing

2.9 The degree of belonging of mechanical processing $k_{m}=0,06 n_{m}$ $/ \mathbf{n}$



Fig. 10: Graph degree of belonging of mechanical processing
2.10 The degree of dispersion $k_{r z}=0,012\left(1-V_{k} / V\right)$

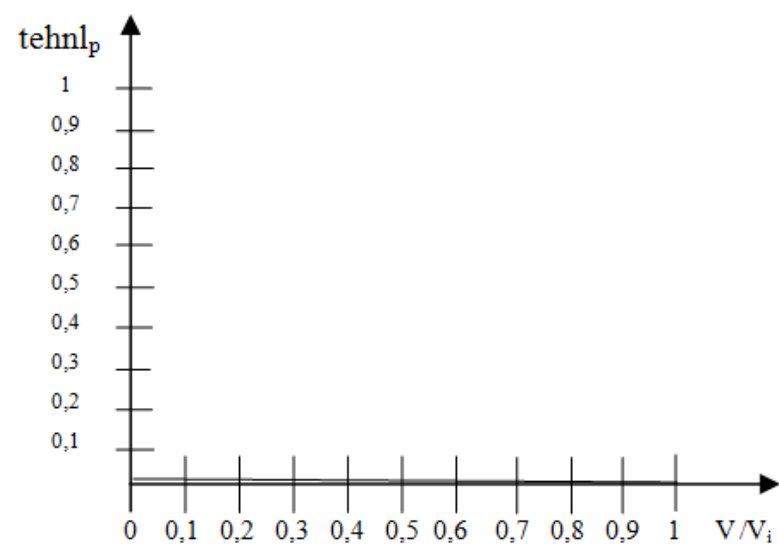

Fig.11: Graph - degree of dispersion

Translated into the final fuzzy variable expression it gets the following form:

$\operatorname{IF0}, 15\left(n_{\mathrm{p}} / \mathrm{n}\right) \mu_{\mathrm{p}}, 0,18\left(\mathrm{n}_{\mathrm{s}} / \mathrm{n}\right) \mu_{\mathrm{s}}, 0,094\left(\mathrm{n}_{\mathrm{j}} / \mathrm{n}\right) \mu_{\mathrm{j}}, 0,12\left(\mathrm{n}_{\mathrm{t}} / \mathrm{n}\right) \mu_{\mathrm{t}}, 0,012\left(\mathrm{G}_{\mathrm{i}} / \mathrm{G}\right) \mu_{\mathrm{G}}, 0,12\left(\mathrm{n}_{\mathrm{od}} / \mathrm{n}\right) \mu_{\mathrm{od}}, 0,24\left(\mathrm{n}_{\mathrm{ot}} / \mathrm{n}\right) \mu_{\mathrm{ot}}, 0,12\left(1-\mathrm{n}_{\mathrm{r}} / \mathrm{n}\right) \mu_{\mathrm{t}}$, $0,06\left(\mathrm{n}_{\mathrm{m}} / \mathrm{n}\right) \mu_{\mathrm{m}}, 0,12\left(1-\mathrm{V} / \mathrm{V}_{\mathrm{i}}\right) \mu_{\mathrm{V}}$, THEN tehnl $\mathrm{p} \min \left(\mu_{\mathrm{n}}, \mu_{\mathrm{V}}, \mu_{\mathrm{G}}\right)$

\section{$4 \quad$ Fuzzy modeling of variables}

This model is realized in the quantity of machine parts (recurring, standard, uniform, with increased accuracy and IT6 IT5, casted, forging, with manual and mechanical processing) of used volumes and materials of finished workpieces. Since this is for the same workpieces, just weight is modeled.

In modeling of weight we take size series for individual and small batch production, because the new design - special products are done in small series.

Models for the quantity of workpieces have the following forms:

The degree of belonging to the number of machine parts depends on their quantity fig. 12 and the expressions (5.1) (5.4).

$\mathrm{KD}$ (quantity of parts) $=\{$ small quantity, medium quantity, a large quantity $\}=\{\mathrm{MK}, \mathrm{SK}, \mathrm{VK}\}$

Table 1: Sizes of series for on individual production

\begin{tabular}{|l|l|l|}
\hline $\begin{array}{l}\text { Parts of large dimensions and weight } \\
>30 \mathrm{~kg}\end{array}$ & $\begin{array}{l}\text { Parts of medium dimensions and } \\
\text { weight } \\
8 \div 30 \mathrm{~kg}\end{array}$ & $\begin{array}{l}\text { Parts of small dimensions and weight } \\
<8 \mathrm{~kg}\end{array}$ \\
\hline$\leq 5$ & $\leq 10$ & $\leq 100$ \\
\hline
\end{tabular}




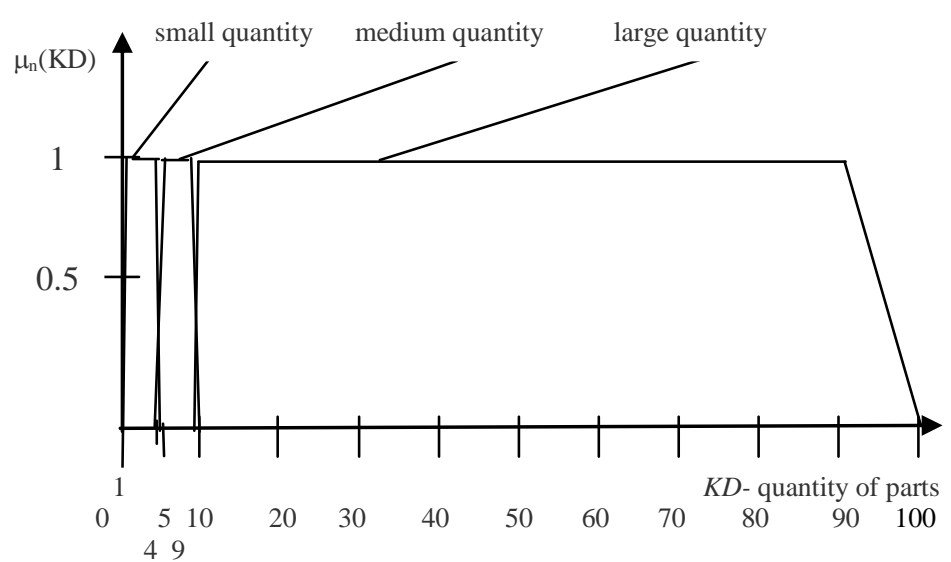

Fig. 12: functions of membership of the number of machine parts

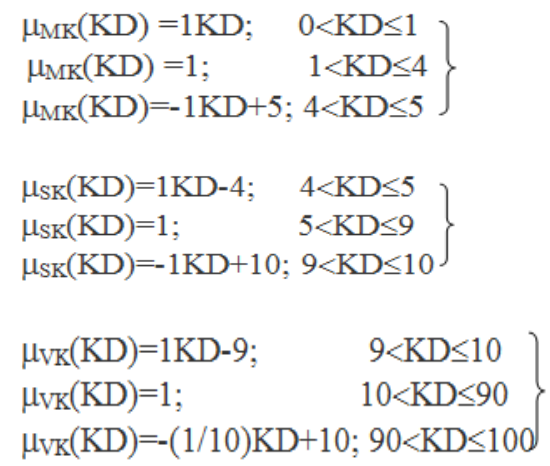

Level - utilization of material of machine parts depends on the weight fig. 13 and the expressions (5.5) - (5.8). IT $($ utilization of weight $)=\{$ light weight, medium weight, great weigh $\} t=\{$ AT, ST, VT $\}$

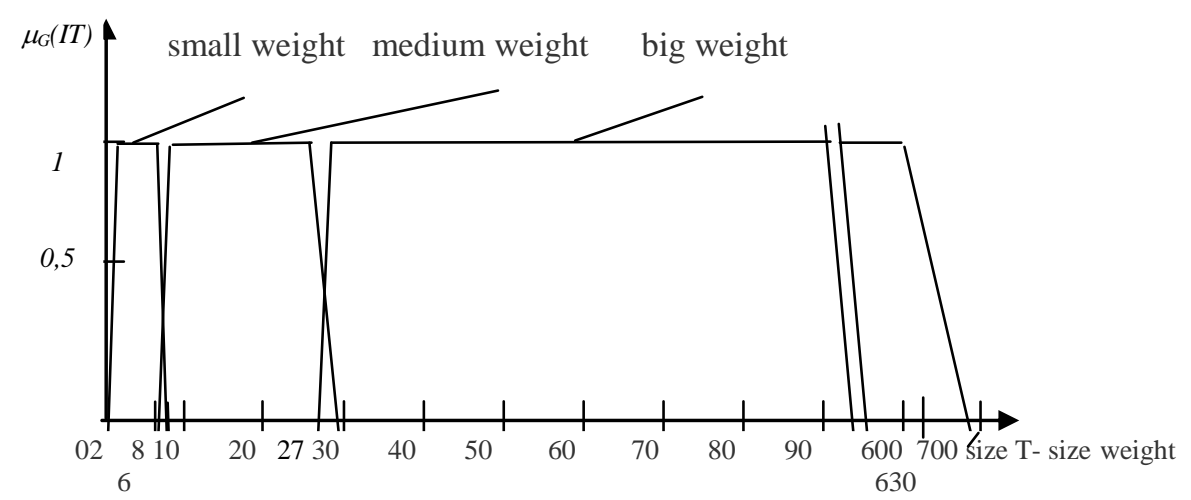

Fig 13: Function - membership of material

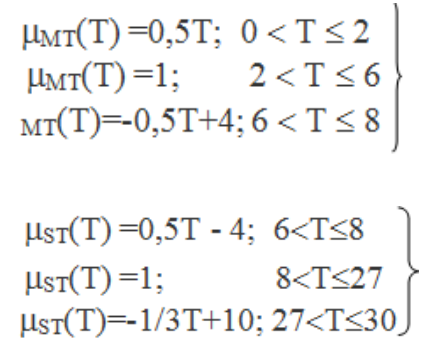




$$
\left.\begin{array}{ll}
\mu \vee \mathrm{VT}(\mathrm{T})=1 / 3 \mathrm{~T}-10 ; & 27<\mathrm{T} \leq 30 \\
\mu \mathrm{VT}(\mathrm{T})=1 ; & 30<\mathrm{T} \leq 90 \\
\mu \mathrm{VT}(\mathrm{T})=-(1 / 10) \mathrm{T}+10 ; & 90<\mathrm{T} \leq 100
\end{array}\right\}
$$

\section{Testing of expression of manufacturability of products}

To test manufacturability of products we is take product - Grinding machine for externally cylindrical grinding of valves.

Special grinding machine for valves has a new assembly housing for the main motion. In fact,

for the entire product of grinding machines new parts are the parts of mentioned housing. Here are the vital parts of the housing and the spindle, and auxiliary parts - pulleys and gear unit of axle belt, lids, etc. So, the number of new parts is twenty of all 45 parts.

We can say that: $\mathrm{n}=45, \mathrm{n}_{\mathrm{p}}=20, \mathrm{n}_{\mathrm{s}}=5, \mathrm{n}_{\mathrm{j}}=2, \mathrm{G}_{\mathrm{i}}=$ about $500 \mathrm{~kg} . \mathrm{V}_{\mathrm{i}}=$ about $70 \mathrm{dm}^{3}, \mathrm{G}=$ about $550 \mathrm{~kg}, \mathrm{~V}=$ approx $75 \mathrm{dm}{ }^{3}$, $\mathrm{n}_{\mathrm{od}}=1, \mathrm{n}_{\mathrm{ot}}=0, \mathrm{n}_{\mathrm{r}}=1, \mathrm{n}_{\mathrm{t}}=5, \mathrm{n}_{\mathrm{m}}=19$.

For named grinder function of manufacturability of products we get the following values:

$\mathrm{k}_{\mathrm{p}}=0,15(20 / 45), \mathrm{k}_{\mathrm{s}}=0,18(5 / 20), \mathrm{k}_{\mathrm{j}}=0,094(2 / 20), \mathrm{k}_{\mathrm{t}}=0,12\left(\mathrm{n}_{\mathrm{t}} / \mathrm{n}\right), \mathrm{k}_{\mathrm{G}}=0,012(500 / 550), \mathrm{k}_{\mathrm{r}}=0,012(1-1 / 20), \mathrm{K}_{\mathrm{od}}=$ $0,12(1 / 20), \mathrm{k}_{\mathrm{ot}}=0,24(0 / 20), \mathrm{k}_{\mathrm{m}}=0,06(19 / 20) \mathrm{k}_{\mathrm{rz}}=0,012(1-70 / 75)$.

We get the following values for the degrees of membership:

$\mathrm{k}_{\mathrm{p}}=0,0667, \mathrm{k}_{\mathrm{s}}=0,045, \mathrm{k}_{\mathrm{j}}=0,0094, \mathrm{k}_{\mathrm{t}}=0,0114, \mathrm{k}_{\mathrm{G}}=0,0114, \mathrm{k}_{\mathrm{r}}=0,0109, \mathrm{k}_{\mathrm{od}}=0,0006, \mathrm{k}_{\mathrm{ot}}=0, \mathrm{k}_{\mathrm{m}}=0,059$ and $\mathrm{k}_{\mathrm{rz}}=$ 0,0008 .

Membership degrees of fuzzy membership functions are: $n_{p}=20, n_{s}=5, n_{j}=2, n_{o d}=1, n_{o t}=0, n_{r}=1, n_{t}=5, n_{m}=19, G_{i}$ $=500 \mathrm{~kg}, \mathrm{~V}_{\mathrm{i}}=70 \mathrm{dm}^{3} \mathrm{su}: \mu_{\mathrm{p}}=1, \mu_{\mathrm{s}}=0$ ili $1, \mu_{\mathrm{j}}=1, \mu_{\mathrm{t}}=0$ ili $1, \mu_{\mathrm{r}}=1, \mu_{\mathrm{od}}=1, \mu_{\mathrm{ot}}=0, \mu_{\mathrm{m}}=1, \mu_{\mathrm{G}}=1, \mu_{\mathrm{rz}}=1$.

\section{Discussion of test results}

The test results of manufacturability products are: $\mathrm{k}_{\mathrm{p}}=0,0667, \mu_{\mathrm{p}}=1, \mathrm{k}_{\mathrm{s}}=0,045, \mu_{\mathrm{s}}=0$ ili $1, \mathrm{k}_{\mathrm{j}}=0,0094, \mu_{\mathrm{j}}=1, \mathrm{k}_{\mathrm{t}}=$ $0,0114, \mu_{\mathrm{t}}=0$ ili $1, \mathrm{k}_{\mathrm{G}}=0,0114, \mu_{\mathrm{G}}=0$ ili $1, \mathrm{k}_{\mathrm{r}}=0,0109, \mu_{\mathrm{r}}=1, \quad \mathrm{k}_{\mathrm{od}}=0,0006, \mu_{\mathrm{od}}=1, \mathrm{k}_{\mathrm{ot}}=0, \mu_{\mathrm{ot}}=0, \mathrm{k}_{\mathrm{m}}=0,003, \mu_{\mathrm{m}}=1$ $\mathrm{i} \mathrm{k}_{\mathrm{rz}}=0,0008, \mu_{\mathrm{rz}}=1$.

It can be said that all degrees of fuzzy variables except quantity of standard and accuracy hav value of 1 . The amount of parts that is standard and of special accuracy should be increased at least by 1, and be produced in small series and not in individual production. The amount of parts is a large amount of VK Fig.11., becouse of the weight of spindle that is greater than $5 \mathrm{~kg}$ and less than $27 \mathrm{~kg}$.

The highest values of manufacturability of products have degrees of belonging: $\mathrm{k}_{\mathrm{p}}=0,0667 \mathrm{i} \mathrm{k}_{\mathrm{s}}=0,045$, and the lowest values are: $\mathrm{k}_{\mathrm{ot}}=0, \mathrm{k}_{\mathrm{od}}=0,0006, \mathrm{k}_{\mathrm{rz} . .}=0,0008$ and $\mathrm{k}_{\mathrm{G}}=0,0094$.

For the greatest value we can say it is very important to have a large number of mechanical parts that are repeated and with it a great savings in time becouse of the constructive and technological documentation. For the smallest value we can say there is no forging which is a loss for profitable production. Casting is the shell - 1 piece of such machine parts is very small. Diversity and high use of materials - the loss of volume and weight of the workpieces is great because $95 \%$ of all machine parts are get by cutting process.

\section{Management of manufacturability of products}

Manufacturability of product is limited to minimum value of 0.15 . If it is less than this value the design is repeated is in Figure 14.

We take this value because of all degrees of belonging $k_{\mathrm{p}}, \mathrm{k}_{\mathrm{m}}, \mathrm{k}_{\mathrm{g}} \mathrm{i} \mathrm{k}_{\mathrm{rz}}$ can achieve the maximum value of 0.32 , the other degrees have minimum values. For example was manufacturability of product 0.1592 .

All of the input values in Fig. 13 are obtained from the manufacturing management software. All quantities are achieved by identification number. Specifically are identified machine parts that are processed in the company $n$ and $n_{p}$, then standard machine elements $n_{s}$, especially uniform $n_{j}$ group with the help of group and typical technologies.

Special request for production management software is determination of the weight and volume of the processed workpiece and machine parts. Also, the recording and searching in the same software we get: $\mathrm{n}_{\mathrm{t}}, \mathrm{n}_{\mathrm{m}}$ and $\mathrm{n}_{\mathrm{r}}$. 


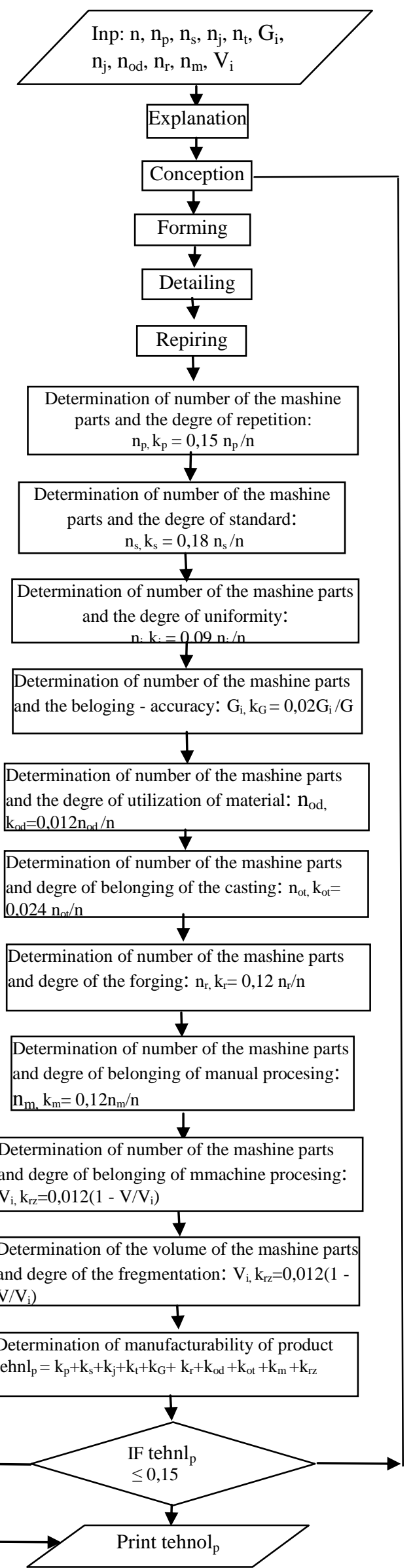

Fig. 14: A rought flow chart of manufacturability 


\section{References}

[1] Tiro, D.: Improvement "Methods for the determination and improvement of the manufacturability - product " connecting with integrated computer information system, 4 Scientific conference "Quality 2005" Fojnice, B \& H. (2005), pp.123-129.

[2] Antic, R. Technological systems, scripts, Higher Schol of Applied Professional Studies, Vranje, (2010), pp. 54-56.

[3] Perinić, M. Tehnological analizis of product,(2012),pp.3,4,www.riter. uniri $/$ zvd pro stroj/katedre/kpp/CO/OTP pdf.

[4] DJapic, M. Evidential systems in developing products and processes, Lola institute, Vol. 9, ISBN 86-906-973-0-6, Belgrade, (2004), pp. 130134 .

[5] Antic, R., Djapic, M., Lukic, LJ. IMPROVEMENT OF THE CHARACTERISTCS OF CAD SYSTEM, WORKING METAL CUTTING, USING FUZZY LOGISTIC DESIGN-PRODUCTS OF WORKPIECE Metalurgia international, Vol. XVII, No 12, ISSN 1582-2214, Romania, (2012), pp. 39-43.

[6] Radivoje Antic, Mirko DJapic, Ljubomir Lukic, Improvement of the characteristcs of CAD system, working metal cutting, using fuzzy logistic design-products of workpiece, METALURGIA INTERNATIONAL, Vol 17, No. 12 - (2012), ISSN 1582-2214, pp. 39-43,.

[7] Radivoje Antic, Mirko Djapic, Dragan Lukic, Application of the parts logistic design process planning with the FUZZYCAPP metal processing by cutting metal processing by cuting, METALURGIA INTERNATIONAL, Vol 17, No. 7 - (2012, ISSN 1582-2214, (2012), pp. $79-86$.

[8] Radivoje ANTIC, Slavica CVETKOVIC, Milan CVETKOVIC, Defining of Manufacturability - manufacturing process - metal cutting by fuzzy logic for design Product, METALURGIA INTERNATIONAL, (2013), pp 01-06.

[9] Xu, X., W., Wang, H., Mao, J., Newman, S., T., Kramer, T., R:, Proctor, F., M., Michalovski, J., I., STEP -compliant NC research; the search for intelligent CAD/CAPP/CAM/CNC integracion, International Journal of production Research, Vol. 43, No 17, (2005), pp. $3703-3743$.

[10] Bramal, D., G., Mckay, K., R., Rogers, B., C., Chapman, P., Cheung, W., M., Maropoulos, P., G., Manufacturability analysis of early product designs, INT. J. COMPUTER INTEGRATED MANUFACTURING, (2003), VOL. 16, NO. 7-8, pp. 501-508.

[11] I., Ferrera, , J., Rios, J., Ciurana, An approach to integrate manufacturing process information in part design phases, journal of materials processing technology 209 , (2009), pp. 2085-2091. 